\title{
Atrial Septal Defect Closure by Anterior Mini Thoracotomy with Total Peripheral Cannulation: A Step towards Establishing Mini Invasive Cardiac Surgery in a Developing Nation
}

\author{
Prabhat Khakural*, Ravi Baral, Anil Bhattarai, Bhagawan Koirala
}

Department of Cardiothoracic and Vascular Surgery, Manmohan Cardiothoracic Vascular and Transplant Center, Institute of Medicine, Maharajgunj, Kathmandu, Nepal

Email:*pkhakural@gmail.com

How to cite this paper: Khakural, P., Baral, R., Bhattarai, A. and Koirala, B. (2020) Atrial Septal Defect Closure by Anterior Mini Thoracotomy with Total Peripheral Cannulation: A Step towards Establishing Mini Invasive Cardiac Surgery in a Developing Nation. World Journal of Cardiovascular Surgery, 10, 192-199. https://doi.org/10.4236/wjcs.2020.1010022

Received: August 24, 2020

Accepted: October 23, 2020

Published: October 26, 2020

Copyright $\odot 2020$ by author(s) and Scientific Research Publishing Inc. This work is licensed under the Creative Commons Attribution International License (CC BY 4.0).

http://creativecommons.org/licenses/by/4.0/

\begin{abstract}
Background: Atrial Septal Defect (ASD) closure is a common cardiac surgical procedure performed worldwide. Due to favourable clinical outcome, minimal invasive approach is becoming popular. Hence this study was conducted to compare the outcome of two surgical approaches, median sternotomy and mini thoracotomy with total peripheral cannulation, in a developing country Nepal. Methods: A prospective study of 62 ASD patients, randomized to undergo surgical closure either via right anterior mini thoracotomy or median sternotomy was conducted and followed up over three years. The clinical outcome parameters like intensive care unit stay, hospital stay, post-operative duration of ventilation, cardiopulmonary bypass time, aortic cross clamp time, mediastinal drainage, size of scar and complication were compared between two groups. Results: Cardiopulmonary bypass time and aortic cross clamp time were significantly longer in right anterior mini thoracotomy group as compared to median sternotomy group (43.97 $\mathrm{min} \pm$ $12.70 \mathrm{~min}$ vs $34.42 \mathrm{~min} \pm 10.42 \mathrm{~min}$ and $25.13 \mathrm{~min} \pm 7.82 \mathrm{~min}$ vs $19.48 \mathrm{~min} \pm$ 6.93 min respectively, $\mathrm{p}$-value $<0.05)$. There was no significant difference in duration of surgery ( $2.75 \mathrm{hrs} \pm 0.43 \mathrm{hrs}$ vs $2.56 \mathrm{hrs} \pm 0.41 \mathrm{hrs}$, p-value $=0.09)$, post-operative ventilation $(2.90 \mathrm{hrs} \pm 1.22 \mathrm{hrs}$ and $2.88 \mathrm{hrs} \pm 1.07 \mathrm{hrs}$, p-value $=0.96$ ) between two groups. Post-operative mediastinal drainage was significantly less in right anterior mini thoracotomy group $(214.52 \mathrm{ml} \pm 91.79 \mathrm{ml}$ vs $284.03 \mathrm{ml} \pm 158.91 \mathrm{ml}, \mathrm{p}$-value $=0.04)$. There was no significant difference in
\end{abstract}


ICU stay and hospital stay. Conclusion: Atrial septal defect can be safely closed by right anterior mini thoracotomy with a small, cosmetically acceptable submammary scar with less pain and bleeding.

\section{Keywords}

Atrial Septal Defect, Mini Thoracotomy, Total Peripheral Cannulation

\section{Background}

Atrial Septal Defect (ASD) is one of the common cardiac malformations, approximately $6.7 \%$ [1]. Although these malformations are often asymptomatic [2], if uncorrected, they may lead to irreversible pulmonary hypertension, progressively declining cardiac function and early death [3]. Median sternotomy (MS) has been the gold standard approach in cardiac surgery because almost all aspects of the heart can be reached and complex measures such as revascularization, valve surgery and procedures for arrhythmia can be executed. However, MS requires a large surgical wound around the sternum that can cause bleeding from bone marrow that occasionally requires blood transfusion and results in mediastinitis, which is often a critical complication although ASD itself is not a critical disease. In contrast, minimally invasive approaches like right anterior mini thoracotomy (RAMT) with cannulation of femoral artery, femoral vein and internal jugular vein delivers the benefits of smaller, less painful wounds, shorter hospital stay, more rapid postoperative recovery and cost reductions and has become a feature of cardiac surgery [4] [5]. Preferable results of minimally invasive ASD closure have been reported and Vida et al. had obtained excellent cosmetic results [6] [7] [8]. However, mini invasive cardiac surgery is in an early phase of development, in low resource countries. Hence this study was aimed to compare the clinical outcomes in ASD closure by RAMT with total peripheral cannulation and MS in a developing country like ours.

\section{Methods}

Sixty two patients of ostium secundum ASD, at Manmohan Cardiothoracic Vascular and Transplant Center, Kathmandu, Nepal from December 2014 to June 2016 were randomized into two groups (ASD closure via MS and ASD closure via RAMT with total peripheral cannulation), operated and followed prospectively. All the patients above 14 years of age, requiring ASD closure were included in the study. However, patients weighing less than $25 \mathrm{~kg}$, those requiring other concomitant cardiac procedures and those with previous thoracic surgery/infection were excluded from study. Approval was obtained from institutional review committee for the study. In RAMT group, patients underwent standard general anesthesia, a right sub-mammary incision of $6 \mathrm{~cm}$ or less with anterior thoracotomy, internal jugular vein, femoral artery and femoral vein 
cannulation, initiation of cardiopulmonary bypass (CPB), use of antegrade cardioplegia and ASD closure with autologous pericardial patch. An extra-pleural catheter was placed passing from 3rd to 5th space for analgesia $(50 \mathrm{ml}$ of fluid consisting of $44 \mathrm{ml}$ of $0.9 \%$ normal saline, $1 \mathrm{ml}$ of 50 micrograms of Fentanyl and $5 \mathrm{ml}$ of $0.5 \%$ Bupivacaine). MS group differed from RAMT in having a standard median sternotomy, central cannulation of superior and inferior vena cava and aorta. Standard Intensive care was provided to the patients. All the vital parameters, amount of drain, inotrope requirement was recorded. Decision to transfer the patient out of intensive care unit and hospital was made by the operating team based on the general condition, amount of drain, inotrope requirement and X-ray findings of the patients. Wound was inspected for any local complications. All the study parameters (ICU stay, hospital stay, post-operative duration of ventilation, CPB time, Aortic Cross clamp (ACC) time, length of surgical scar, pain score(measured with numeric pain scale, in post-operative period after extubation, eight hours after extubation and whenever patients complained of pain), amount of drainage, complications) was recorded as per the proforma and analyzed. The data were analyzed using Statistical Program for Social Sciences (SPSS) version 23. Values were expressed as means \pm standard deviations or as frequencies and proportions. Quantitative parametric data were compared using an independent samples t-test. The $p$ values of $<0.05$ were considered significant.

\section{Results}

31 patients were included in each group. Maximum patients (54.01\%) were in the age group of $14-24$ years. The youngest patient with ASD was 14 years old and the oldest was 61 years old. Mean age of patients in MS group was $26.45 \pm$ 11.59 years and that in RAMT group was $24.55 \pm 10.82$ years ( $\mathrm{p}$ value $=0.50$ ). The female: male ratio in MS group was 1.8:1 and it was 2.8:1 in RAMT group (Table 1). Majority of the patients presented with exertional shortness of breath; 20 (64.51\%) in MS group vs 18 (58.06\% in RAMT group) followed by occasional palpitation; 5 (16.12\%) in MS group vs 7 (22.58\%) in RAMT group. Intraoperative variables (Table 2) analyzed found the groups were comparable in relation to the ASD size.

Postoperative variables (Table 3 ) analysis did not find significant difference in postoperative ICU and hospital stay between the groups. Long term follow up of these patients revealed a hundred percentage survival and freedom from reoperation at 3 years. However, 3 patients in the MS group had hypertrophic scar with itching and infrequent paresthesia and all of the patients were concerned about having a sternal foreign body (steel wires) in the MS group. Patients in the RAMT group were satisfied with the cosmetic scar and absence of foreign body in their wound. Comparing the above findings, atrial septal defect closure by right anterior mini thoracotomy had some advantages over median sternotomy approach (Table 4). 
Table 1. Demographics of the patients in two groups.

\begin{tabular}{lcc}
\hline & MS group (N-31) & RAMT group \\
\hline Gender: N, (\%) & Male: $11(35.48 \%)$ & Male: $8(25.80 \%)$ \\
\hline Age Distribution: N, (\%) & Female: $20(64.51 \%)$ & Female: $23(74.19 \%)$ \\
14 - 24 years & $15(48.38 \%)$ & $18(58.06 \%)$ \\
25 - 34 years & $8(25.80 \%)$ & $8(25.80 \%)$ \\
35 - 44 years & $6(19.35 \%)$ & $4(12.9 \%)$ \\
45 - 54 years & $1(3.22 \%)$ & $1(3.22 \%)$ \\
55 - 64 years & $1(3.22 \%)$ & $18(58.06 \%)$ \\
\hline Chief presenting symptom N, (\%) & & $7(22.58 \%)$ \\
Exertional Dyspnoea & $20(64.51 \%)$ & $6(19.35 \%)$ \\
Palpitation & $5(16.12 \%)$ & \\
Asymptomatic & $6(19.35 \%)$ &
\end{tabular}

MS: Median Sternotomy; RAMT: Right Anterior Mini Thoracotomy.

Table 2. Intraoperative variables.

\begin{tabular}{cccc}
\hline Variables & $\begin{array}{c}\text { MS group } \\
(\mathrm{n}=31)\end{array}$ & $\begin{array}{c}\text { RAMT group } \\
(\mathrm{n}=31)\end{array}$ & P value \\
\hline Atrial Septal Defect size (cm) & $2.51 \pm 0.79$ & $2.210 \pm 0.71$ & 0.11 \\
Cardiopulmonary bypass time (min) & $34.42 \pm 10.62$ & $43.97 \pm 12.70$ & 0.002 \\
Aortic Cross Clamp Time (min) & $19.48 \pm 6.93$ & $25.13 \pm 7.82$ & 0.004 \\
Duration of Surgery (hrs) & $2.56 \pm 0.41$ & $2.75 \pm 0.43$ & 0.09 \\
\hline
\end{tabular}

MS: Median Sternotomy; RAMT: Right Anterior Mini Thoracotomy.

Table 3. Postoperative findings.

\begin{tabular}{cccc}
\hline Variable & MS group & RAMT group & P value \\
\hline Postoperative duration of ventilation (hrs) & $2.88 \pm 1.07$ & $2.90 \pm 1.22$ & 0.96 \\
Mediastinal Drainage (ml) & $284.03 \pm 158.91$ & $214.52 \pm 91.79$ & 0.04 \\
Pain Score & $4.13 \pm 0.49$ & $3.42 \pm 0.72$ & $<0.01$ \\
ICU stay (days) & $1.97 \pm 0.75$ & $2.06 \pm 0.51$ & 0.55 \\
Hospital Stay (days) & $3.74 \pm 1.15$ & $3.84 \pm 1.12$ & 0.74 \\
Length of Scar (cm) & $12.32 \pm 1.04$ & $5.06 \pm 0.33$ & $<0.01$ \\
\hline
\end{tabular}

MS: Median Sternotomy; RAMT: Right Anterior Mini Thoracotomy. 
Table 4. Comparison of advantages of the approaches.

\begin{tabular}{ccc}
\hline Variables & MS group & RAMT group \\
\hline Scar length & Long & Short \\
Hypertrophic scar & Present & Absent \\
Mediastinal Drainage & More & Less \\
Pain Score & More & Less \\
Patient Satisfaction & Less & More
\end{tabular}

MS: Median Sternotomy; RAMT: Right Anterior Mini Thoracotomy.

\section{Discussion}

Atrial septal defect is more common in females as compared to males. Our study also showed a female preponderance (Female: male-2.2:1), which is a finding similar to that seen in a study Bigdelian et al. [9]. In our study, the mean age of the patients was $25.50 \pm 11.16$ years. It was $26.45 \pm 11.59$ years in median sternotomy group whereas $24.55 \pm 10.82$ years in mini thoracotomy group with a $\mathrm{p}$ value of 0.507 signifying that the two groups were comparable in age factor. In a study by Tarek et al. the mean age of the patients was $15.6 \pm 6.8$ years and $18.3 \pm$ 6.1 years in anterolateral thoracotomy and MS categories, respectively [10]. We found the mean length of surgical scar was $5.06 \pm 0.33 \mathrm{~cm}$ in RAMT group whereas $12.32 \pm 1.04 \mathrm{~cm}$ in MS group (p value $<0.01$ ). Hu et al. found the length of incision in mini thoracotomy was $6.3 \pm 1.1 \mathrm{~cm}$, which was significantly shorter than $9.6 \pm 2.5 \mathrm{~cm}$ long incision in sternotomy group [11]. Hence young females and those who are cosmetically conscious prefer mini thoracotomy to median sternotomy approach. In a meta-analysis conducted by Ding et al., mini thoracotomy had significantly longer CPB time ( $8.00 \mathrm{~min}$ more, $95 \%$ CI -0.36 to $15.64 \mathrm{~min}, p=0.04$ ) [12]. The smaller incision, limited working space increase the $\mathrm{CPB}$ time and ASD closure time. In a retrospective Japanese study, ACC time was longer in the right thoracotomy group than in the MS group (45 \pm 17 min vs $23 \pm 9 \mathrm{~min}, p=0.004$ ) [13]. Adhikary et al., found that the mean total operation time was $217.33 \pm 21.65 \mathrm{~min}$ in ASD closure via thoracotomy [14]. RAMT requires compressing on the right lung to gain access to the pericardium and makes patients more prone to development of atelectasis. This may lead to longer duration of post-operative ventilation. However, this problem can be taken care of with positive pressure lung inflation during thoracotomy closure and adequate analgesia via extra-pleural catheter. Tarek et al. found the mean duration of ventilation was $12.1 \pm 8.5$ hours in thoracotomy group and $13 \pm 8.4$ hours in sternotomy group [10]. MS is theorized to have more mediastinal bleeding because of the long incision of the sternum with greater raw area in the bone whereas in mini-thoracotomy, there is small incision on the skin and muscles are divided with the use of electrocoagulation, thereby reducing the surface for bleeding. Ishida et al. found that significantly less intraoperative blood was 
lost by the right thoracotomy group than the MS group ( $89 \pm 53 \mathrm{~mL}$ vs $209 \pm$ $142 \mathrm{~mL}, p=0.01$ ) [13]. However, the total amount and duration of blood drainage did not significantly differ between the two groups. Thoracotomy patients have the advantages of small incision, less pain, early extubation, less mediastinal drainage, early drain removal, early ambulation and hence they tend to have a shorter ICU stay and hospital stay. However in our study, no significant difference was found in the ICU stay and hospital stay amongst the groups. One study showed, the mean length of stay in the intensive care unit was 2 days and the mean length of hospital stay was 4.5 days [9]. The length of stay in the ICU and hospitalization did not significantly differ between the two groups in other studies [13]. In our study, pain management in RAMT group was done with infusion of analgesic solution (Bupivacaine, Fentanyl, and Normal Saline) through the extrapleural catheter and intravenous Fentanyl in SOS basis. In MS group, pain management was done by intravenous Fentanyl and Paracetamol in the first 24 hours. Then patients were switched to oral analgesics like Paracetamol and Ketorol. The mean pain score in thoracotomy group was $3.42 \pm 0.72$ and in median sternotomy group was $4.13 \pm 0.49$ ( $\mathrm{p}$ value $<0.01$ ). In a similar study by Baral et al., no significant difference was found in the pain score in two groups [15]. The complication rate in our study was $11.29 \%$. There were only three cases of superficial surgical site infection in patients undergoing ASD closure by median sternotomy and two cases of superficial surgical site infection in ASD closure via mini thoracotomy patients. In thoracotomy group, one patient had femoral vein thrombosis and one patient had femoral artery thrombosis for which thrombectomy had to be performed. There were no cases of breast deformity, re-exploration, limb loss and arrhythmia and in hospital deaths. In our previous experiences, patients with ASD closure used to have a longer stay in ICU and hospital. But with the progress of surgical experience and better intensive care facility the ICU stay and hospital stay have come down. Since the cost of the cannulae used, hospital stay and intensive care unit stay were similar in this study, there was no difference in the surgical expenses in two groups.

\section{Limitations of the Study}

This was a single hospital based study, done over a limited period with a small sample size. Quantification of pain is always a difficult matter. Although the use of numeric pain scale helps to quantify it, the subjective perception of intensity of pain varies amongst individuals.

\section{Conclusion}

We found a shorter surgical scar, less mediastinal drainage and lower pain score in RAMT group. There were no differences in postoperative ventilation duration, ICU stay and hospital stay. CPB and ACC time were significantly shorter in MS group. Although statistically insignificant, the operative time was less in MS group than RAMT group. Patients were satisfied with the smaller incision and 
perceived that they had the better cosmetic results, besides having less pain in immediate postoperative period as well as in long term follow up. There was no mortality, limb loss or any other major complication. Hence we conclude that ASD can be closed safely by mini thoracotomy incision with total peripheral cannulation with a better long term cosmetic result.

\section{Conflicts of Interest}

The authors declare no conflicts of interest regarding the publication of this paper.

\section{References}

[1] Fulton, D.R. (2008) Congenital Heart Disease in Children and Adolescents. In: Fuster, V., O'Rourke, R.A., Walsh, R.A., Poole-Wilson, P., Eds., Hurst's the Heart, 12th Edition, McGraw-Hill Co., New York, 1855-1921.

[2] Seldon, W.A., Rubstein, C. and Fraser, A.A. (1962) The Incidence of Atrial Septal Defect in Adults. British Heart Journal, 24, 552-562. https://doi.org/10.1136/hrt.24.5.557

[3] Bonow, R. and Borer, J.S. (1981) Left Ventricular Functional Reserve in Adults with Atrial Septal Defect: Pre- and Postoperative Studies. Circulation, 63, 1315-1322. https://doi.org/10.1161/01.CIR.63.6.1315

[4] Goldstone, A.B., Atluri, P., Szeto, W.Y., Trubelja, A., Howard, J.L., MacArthur Jr., J.W., et al. (2013) Minimally Invasive Approach Provides at Least Equivalent Results for surgical Correction of Mitral Regurgitation: A Propensity Matched Comparison. The Journal of Thoracic and Cardiovascular Surgery, 145, 748-756. https://doi.org/10.1016/j.jtcvs.2012.09.093

[5] Glauber, M., Miceli, A., Gilmanov, D., Ferrarini, M., Bevilacqua, S., Farneti, P.A., et al. (2013) Right Anterior Minithoracotomy versus Conventional Aortic Valve Replacement: A Propensity Score Matched Study. The Journal of Thoracic and Cardiovascular Surgery, 145, 1222-1226. https://doi.org/10.1016/j.jtcvs.2012.03.064

[6] Doll, N., Walther, T., Falk, V., Binner, C., Bucerius, J., Borger, M.A., et al. (2003) Secundum ASD Closure Using a Right Lateral Minithoracotomy: Five-Year Experiencein 122 Patients. The Annals of Thoracic Surgery, 75, 1527-1530. https://doi.org/10.1016/S0003-4975(02)04889-0

[7] Chang, C.H., Lin, P.J., Chu, J.J., Liu, H.P., Tsai, F.C., Chung, Y.Y., et al. (1998) Surgical Closure of Atrial Septal Defect. Minimally Invasive Cardiac Surgery or Median Sternotomy? Surgical Endoscopy, 12, 820-824.

https://doi.org/10.1007/s004649900721

[8] Vida, V.L., Tessari, C., Fabozzo, A., Padalino, M.A., Barzon, E., Zucchetta, F., et al. (2013) The Evolution of the Right Anterolateral Thoracotomy Technique for Correction of Atrial Septal Defects: Cosmetic and Functional Results in Prepubescent Patients. The Annals of Thoracic Surgery, 95, 242-247.

https://doi.org/10.1016/j.athoracsur.2012.08.026

[9] Bigdelian, H., Sedighi, M. and Movahedi, F. (2015) Repair of Atrial Septal Defect via Right Submammary Minithoracotomy in Children. International Cardiovascular Research Journal, 9, 52-54.

[10] El-Sayegh, T.M.M. and. El-Elwany, S.E.M. (2012) Right Antero-lateral Thoracotomy versus Sternotomy for Repair of Atrial Septal Defect in Young Females. Journal 
of the Egyptian Society of Cardio-Thoracic Surgery, 20, 133-136.

[11] Hu, C.X., Tan, J., Chen, S., Ding, H. and Xu, Z.W. (2014) Comparison of Clinical Outcomes and Postoperative Recovery between Two Open Heart Surgeries: Minimally Invasive Right Subaxillary Vertical Thoracotomy and Traditional Median Sternotomy. Asian Pacific Journal of Tropical Medicine, 7, 625-629.

https://doi.org/10.1016/S1995-7645(14)60105-X

[12] Ding, C., Wang, C., Dong, A., Kong, M., Jiang, D., Tao, K., et al. (2012) Anterolateral Minithoracotomy versus Median Sternotomy for the Treatment of Congenital Heart Defects: A Meta-Analysis and Systematic Review. Journal of Cardiothoracic Surgery, 7, Article No. 43. https://doi.org/10.1186/1749-8090-7-43

[13] Ishida, N., Shimabukuro, K., Ogura, H. and Iwata, H. (2015) Atrial Septal Defect Closure through a Right Thoracotomy in Adults. Cardiovascular and Thoracic Open, 1-4. https://doi.org/10.1177/2055552015598061

[14] Adhikary, A.B., Kamal, S., Saha, S.K., Hossain, A., Quader, S.A., et al. (2009) Cosmetic Approach of Atrial Septal Defect Repair through Right Anterolateral Thoracotomy. Bangladesh Medical Research Council Bulletin, 35, 75-76. https://doi.org/10.3329/bmrcb.v35i2.2766

[15] Baral, R.K. and Koirala, B. (2015) Right Anterolateral Thoracotomy an Alternative to Median Sternotomy for Closure of Atrial Septal Defect: A Cosmetic Approach in Young Females. Nepalese Heart Journal, 12.

https://doi.org/10.3126/njh.v12i1.12408

\title{
List of Abbreviations
}

\author{
ASD-Atrial Septal Defect \\ ACC-Aortic Cross Clamp \\ $\mathrm{CPB}-$ Cardiopulmonary Bypass \\ ICU-Intensive Care Unit \\ MS-Median Sternotomy
}

RAMT-Right Anterior Mini Thoracotomy 